\title{
Finite Element Modelling of Off-Road Tyres for Radial Tyre Model Parameterization
}

\author{
J.M. Conradie, P.S. Els, P.S. Heyns \\ Department of Mechanical and Aeronautical Engineering, University of Pretoria, Pretoria, South Africa
}

\begin{abstract}
This paper investigates the possibility of using a coarse finite element model with bulk material properties, to model the vertical force-displacement characteristics of a tyre, for the purpose of tyre model parameterization. The paper proves the approach on a light truck off-road tyre. The practical application is intended, however, for very large tyres where physical testing is not feasible.
\end{abstract}

The paper indicates that it is feasible to obtain bulk material properties from tensile tests on specimens cut from different positions on a tyre and to use these test results to parameterize suitable non-linear anisotropic material models. The non-linear elements defined in the Neo-Hookean and Ogden models, as well as elements with differing linear orthogonal stiffnesses, are combined with each other to simulate the global material properties of the tread and sidewall of the tyre.

The global behaviour of the finite element model is analysed by comparing experimental and simulation data on a flat surface as well as various lateral and longitudinal cleats. The results confirm that the finite element model can predict with acceptable accuracy the vertical force vs. displacement, as well as the sidewall deformation of the tyre under static loading conditions on a flat surface and also on various different cleats, by using equivalent (global) material properties.

The approach is accurate enough to be used in the parameterization of various tyre models.

Keywords: finite element analysis, finite element modelling, experimental testing, non-linear modelling, nonlinear materials, tyre, radial stiffness, quasi-static, off-road

\section{Introduction}

Tyres are usually the only parts of a vehicle that are in contact with the terrain on which the vehicle operates. The interaction between the tyres and terrain largely affects the driving performance and dynamic response of vehicles. Acceleration, braking, steering and cornering forces are all generated in the relatively small contact area between the terrain and the tyres. Tyres are critical to ride comfort because they filter out high-frequency undulations in the terrain. Tyre characteristics have to be well-matched to the vehicle's suspension system to reduce the forces transmitted to the vehicle body, thus improving the vehicle's ride comfort and structural durability. 
Many investigators have developed robust mathematical models to describe the kinematics and dynamics of rolling pneumatic tyres on rigid and non-rigid surfaces. Accurate simulations of tyre deformation can be used to compare the performance of tyres over a wide range of operating conditions and designs [1, 2]. Extensive research has also been done on the characterization and modelling of tyres for use in vehicle dynamics analysis and vehicle design.

Various characterization and modelling studies have been performed on truck tyres [3, 4] and automobile tyres $[5,6,7]$. Tests on large off-road tyres are not common, however, owing to their sheer size and the loads on these tyres. Most tyre models require a fair amount of data before an accurate representation of the tyre can be obtained. For this reason, the development and parameterization of tyre models are expensive. Methods for reducing or simplifying the characterization and parameterization effort may contribute significantly to obtaining the required accuracy at a lower cost.

This paper explores the possibility of using a coarse finite element model, using the bulk material properties obtained from test samples cut from a tyre, in order to obtain vertical force-displacement relationships suitable for tyre model parameterization. Although the envisaged application is for really large tyres where physical testing is either not feasible or extremely costly, the principle is investigated by using a light truck tyre for which experimental validation could be readily performed.

The primary objectives of this paper are to -

- demonstrate how the tyre can be divided into segments that have similar material properties (e.g. tread, sidewall and bead regions);

- measure and model the global behaviour of the composite material of each region of the tyre;

- verify the effectiveness of using sets of superelements to describe anisotropic behaviour;

- develop a tyre model that can accurately represent the static non-rolling behaviour of the tyre;

- $\quad$ validate the model with deformation profiles of the sidewall and radial force vs. displacement curves;

- $\quad$ provide data that can be used to parameterize the existing tyre models for vertical force on rough roads.

A simple tyre model that is divided into three regions only is presented in this paper. The number of elements in the tyre model developed is substantially less than other conventional FE tyre models [8, 9]. This is achieved by combining several material properties of the various parts of a composite tyre into coarse superelements with global material properties.

\section{Tyre models}

Many mathematical models have been developed for tyres with varying levels of complexity and accuracy. Some of these existing tyre models that can be used to simulate ride comfort on rough roads are shown in Figure 1. These models vary from empirical models that use curve fits to full physics-based models.

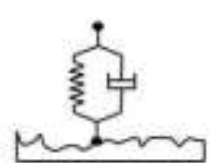

Point contact

(a)

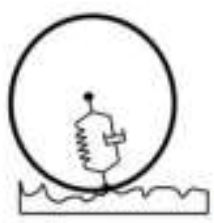

Roller Contact

(b)

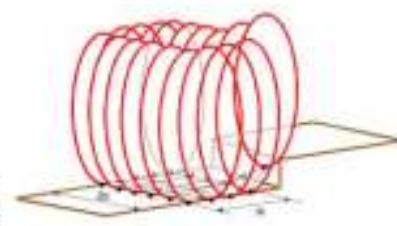

30 Enveloping contact

(c)

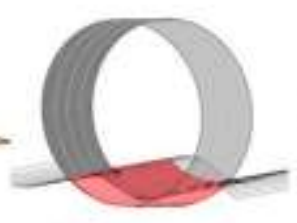

Volume contact

(d)

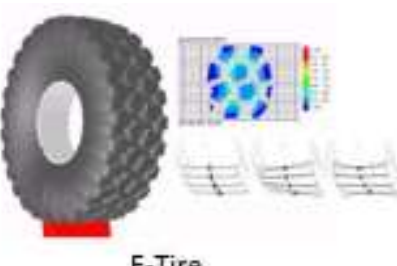

(e)

Figure 1: Classification of tyre models (adapted from [10]) 
Empirical and semi-empirical tyre models are primarily used for modelling lateral and longitudinal force generation over smooth, hard roads for handling and performance analysis. Tables or mathematical formulae and interpolation schemes are used to describe tyre behaviour. These models are usually parameterized with the aid of regression procedures to yield a best fit to the measured data. A well-known empirical model is the Magic Formula (MF) tyre. The MF tyre requires a large amount of experimental data, but the model generates fast and accurate results once the necessary coefficients have been accurately identified [11, 12, 13]. The vertical forces in many empirical models are generated by using some form of contact model. The simplest contact models are the single contact point model [14] (Figure 1a) and the roller contact model [15] (Figure 1b). The 3D enveloping models (Figure 1c) and volume contact models (Figure 1d) give better results than the simpler contact models over discrete obstacles such as cleats, but still rely on fitting some equivalent stiffness and damping parameters to a simplified representation of the contact between the tyre and the terrain. These models are only suitable for use on smooth roads where the shortest wavelength in the road profile is much larger than the tyre contact patch [10]. These models should therefore only be used on smooth roads, not for ride analysis.

Physics-based tyre models often aim to represent the tyre with coarsely discretized masses connected to one another by springs and dampers. Rigid belt and flexible belt models, with linear or non-linear spring and damper elements, are typically used in this type of model $[11,7]$. Some models take tread geometry into account and employ multi-point tyre-terrain contact models. Examples include the FTire [11, 16] (Figure 1e), Hohenheim [17] and RMOD-K models [18, 19]. These models are generally computationally expensive and require large amounts of data for parameterization. They are suitable for ride analysis over rough terrain and short wavelength obstacles, and can usually predict higher frequencies with some accuracy [20, 10].

For parameterization, all these models require geometric as well as stiffness and damping parameters that must be obtained experimentally. Physical testing is the conventional way of obtaining parameterization data for the existing tyre models. Quasi-static tests to determine non-rolling static stiffness, or drop tests to obtain non-rolling dynamic stiffness and damping, can be performed under laboratory conditions. For the tyres of passenger cars and light trucks, drum or flat track tests can be used to obtain lateral, longitudinal and vertical parameters under dynamic conditions, but on simulated road surfaces. In the case of the larger tyres used in the agricultural, construction and mining industries, the tyre size and load make drum or flat track tests impracticable, so large field test rigs are often used, in the form of test trailers . For really large tyres, with diameters in excess of $2 \mathrm{~m}$ and static loads of more than $200 \mathrm{kN}$, none of these methods are feasible, which explains the dearth of useful data about these tyres. One example of such a large tyre is the Michelin 40.00R57 tyre with a diameter of 3570 $\mathrm{mm}$ and width of $1016 \mathrm{~mm}$, carrying a static load in excess of $60000 \mathrm{~kg}$.

The finite element (FE) modelling of tyres dates back to 1973, when the journal Tire Science and Technology was established [21]. Even coarse FE models require many degrees of freedom [1, 14] to achieve acceptable accuracy. The modelling of the composite cord-rubber structural components, as well as suitable material models for rubber, is still an area where insufficient research has been done. The main problem with these components in the tyre is their non-linear properties as well as modelling the bonding between the different elements. FE analyses are nonetheless commonly used for tyre design as well as for investigating noise and durability. The use of superelements with different subsequent material types is commonly used in other fields where finite element modelling is used, however, no evidence was found that this technique has been applied to tyre models before.

The nature and the complexity of a tyre model depend on the type of analysis required. It is established practice to model only the circumferential grooves in the tread in tyre finite element models, but recent research $[6,22]$ indicates that including the detailed tread pattern significantly improves the accuracy of the footprint, contact pressure and lateral behaviour. A difference in the contact stress distribution was also detected [6, 22]. Using only the circumferential grooves does however give almost identical results for lumped variables such as tyre deformation and dynamic radius [6]. 
Most of the detailed finite element models of tyres in the recent literature use linear 8-node hexahedral elements. Different areas of the tyre model can be modelled by using different properties, e.g. the properties of the tread, outer and inner belts, carcass, sidewall, bead, filler and bead bundle can be separately assigned. The most important factors that influence contact area and contact pressure distribution are the tyre inflation pressure and the tyre structure [23].

An example of a non-linear 3D FE tyre model, which considers the structural geometry, the anisotropic material properties of the multiple layers and the nearly incompressible property of the tread rubber blocks was developed by using ANSYS [24]. The belt and carcass layers were modelled with a SOLID 46-element type which includes layer thickness, material direction angles and orthotropic material properties. This element has three degrees of freedom at each node, namely translations along the nodal $\mathrm{x}, \mathrm{y}$ and $\mathrm{z}$ directions. The properties of the nylon, steel belts, rubber, etc. are built into the different layers defined in the SOLID 46 elements [2].

Anisotropic and non-linear material properties are expected because of the complex composite structure of a tyre carcass. The large deformations also mean that the tyre is geometrically highly non-linear. The specific material models used, as well as their parameterization, is crucial to developing a valid FE model.

\subsection{Orthotropic material properties}

The tyre carcass and tread have different material properties in different directions due to the varying orientation of the cords (steel, nylon, polyester, etc.) embedded in the rubber. Materials that have two or three mutually orthogonal planes or axes of symmetry, where material properties are independent of the direction within each plane, are called orthotropic materials.

In these materials, the relationship between the three normal stresses $\sigma_{1}, \sigma_{2}$, and $\sigma_{3}$, and the three shear stresses $\tau_{12}, \tau_{23}$, and $\tau_{13}$ are related to the strains $\varepsilon_{1}, \varepsilon_{2}, \varepsilon_{3}, \gamma_{12}, \gamma_{23}$, and $\gamma_{13}$ is described by Equation 1. $\mathrm{E}_{1}, \mathrm{E}_{2}$ and $\mathrm{E}_{3}$ are the Young's moduli of elasticity along the orthogonal directions 1, 2 and 3 respectively. The Poisson's ratios are represented by $v_{i j}(\mathrm{i}, \mathrm{j}=1,2,3)$, whereas $\mathrm{G}_{12}, \mathrm{G}_{23}$ and $\mathrm{G}_{13}$ are the shear moduli [25].

$\left\{\begin{array}{c}\varepsilon_{1} \\ \varepsilon_{2} \\ \varepsilon_{3} \\ \gamma_{23} \\ \gamma_{13} \\ \gamma_{12}\end{array}\right\}=\left[\begin{array}{ccccccc}\frac{1}{E_{1}} & \frac{-v_{21}}{E_{2}} & \frac{-v_{31}}{E_{3}} & 0 & 0 & 0 \\ \frac{-v_{12}}{E_{1}} & \frac{1}{E_{2}} & \frac{-v_{32}}{E_{3}} & 0 & 0 & 0 \\ \frac{-v_{13}}{E_{1}} & \frac{-v_{23}}{E_{2}} & \frac{1}{E_{3}} & 0 & & 0 & 0 \\ & & & & \frac{1}{G_{23}} & 0 & 0 \\ 0 & 0 & 0 & 0 & \frac{1}{G_{13}} & 0 \\ 0 & 0 & 0 & 0 & \\ 0 & 0 & 0 & 0 & 0 & \frac{1}{G_{12}}\end{array}\right]\left\{\begin{array}{c}\sigma_{1} \\ \sigma_{2} \\ \sigma_{3} \\ \tau_{23} \\ \tau_{13} \\ \tau_{12}\end{array}\right\}$

Equation (1) can be written in compact form as

$\{\varepsilon\}=[S]\{\sigma\}$

where $\{\varepsilon\}$ and $\{\sigma\}$ represent the $6 \times 1$ strain and stress vectors, respectively, and [S] is called the compliance matrix.

The inverse of the compliance matrix $[\mathrm{S}]$ is called the stiffness matrix $[\mathrm{C}]$ and is given as

$\{\sigma\}=[C]\{\varepsilon\}$

Since the compliance matrix is symmetric, the material constants appearing in the compliance matrix in Equation 1 are not all independent, but related by Equations 4 to 6 : 
$\frac{v_{12}}{E_{1}}=\frac{v_{21}}{E_{2}}$

$\frac{v_{13}}{E_{1}}=\frac{v_{31}}{E_{3}}$

$\frac{v_{23}}{E_{2}}=\frac{v_{32}}{E_{3}}$

These equations are called the reciprocity relations for the material constants. It is clear from these relations that there are nine independent material constants for an orthotropic material [25].

\subsection{Hyper-elastic constitutive models}

Rubber-like materials exhibit certain stress-strain characteristics called hyper-elasticity. Several models are available in the literature for these materials. Ghoreishy [1] published a comprehensive review of the finite element models of rolling tyres developed from 1974 to 2008 . The most frequently used formulation for rubber in finite element tyre simulations is the Mooney-Rivlin (first and second order) and Ogden models for hyperelastic materials. These formulations give stable solutions. Other common models used for rubbers are those by Arruda-Boyce and Yeoh, as well as the Neo-Hookean constitutive model. These models are used in several commercial FE codes and are commonly used in tyre models [1, 9, 26, 27]. The Ogden and Neo-Hookean models were used in the present study to obtain the fits for the sample segments shown in Figure 5 and Figure 6.

The Neo-Hookean Model:

$W=C_{10}\left(I_{1}-3\right)$

is a special case of the Mooney-Rivlin form, with $C_{01}=0$. The model uses a single modulus $\left(2 C_{01}=G\right)$ and gives a good correlation for experimental data up to $40 \%$ strain in uniaxial tension [27].

The Ogden Model:

$W=\sum_{n=1}^{N} \frac{\mu_{n}}{\alpha_{n}}\left(\lambda_{1}^{\alpha_{n}}+\lambda_{2}^{\alpha_{n}}+\lambda_{3}^{\alpha_{n}}-3\right)$

$\mathrm{J}$ is the Jacobian measuring dilatancy, defined as the determinant of deformation gradient $\mathrm{F}\left(J=\lambda_{1} \lambda_{2} \lambda_{3}\right)$. The Neo-Hookean and Mooney-Rivlin material models can be considered as special cases from the Ogden model [27].

\section{Experimental testing and measurements}

The tyre used in this study is a Continental 235/85 R $16110 \mathrm{~S}$ off-road tyre designed for use on a Sports Utility Vehicle. The tyre has a section width of $235 \mathrm{~mm}$, an outside diameter of $806 \mathrm{~mm}$ with an aspect ratio of $85 \%$, and is mounted on a 16 -inch rim. The tyre has a radial ply construction, load index of 110 (i.e. the maximum nominal wheel load rating is $10.4 \mathrm{kN})$ and a speed rating of $\mathrm{S}(180 \mathrm{~km} / \mathrm{h})$.

Testing was performed to obtain accurate geometry and the material properties essential to accurate finite element modelling. Tests were also performed to obtain validation data in the form of force-displacement characteristics and the sidewall deformation of the tyre.

\subsection{Geometry}

The tyre sidewall and tread geometry were measured by using displacement lasers (Acuity AR700), a string potentiometer, a shaft encoder, a solid frame for mounting the tyre and an X-Y platform. The measured sidewall and tread profiles, as well as the 3D solid model, are shown in Figure 2. 

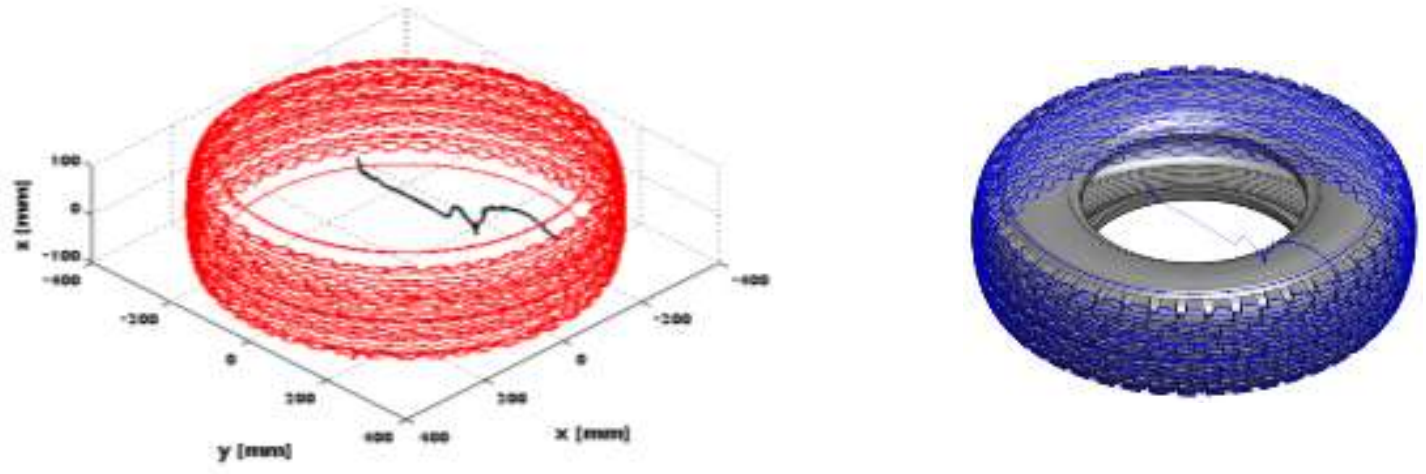

Figure 2: Laser measurements of sidewall and tread geometry (left) and reconstructed solid (CAD) model (right)

\subsection{Material properties}

A Durometer (Shore D TH210) was used to determine the hardness of the rubber in different regions of the tyre, as shown in Figure 3 (left).

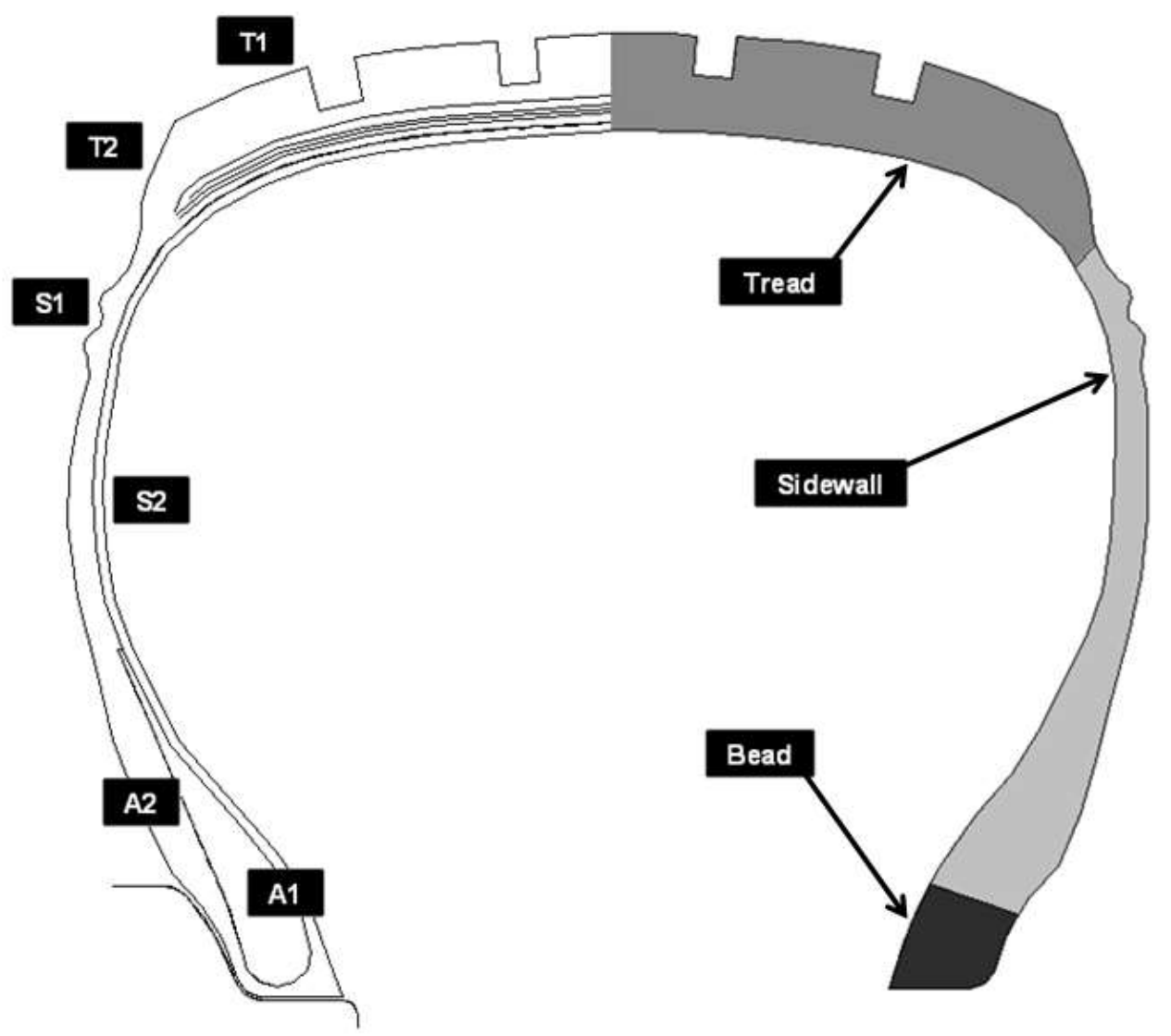

Figure 3: Regions on the tyre measured for Shore D hardness (left) and the regions into which the tyre was divided (right)

Averaged readings of samples of each region (shown in Table 1) were taken to determine the hardness of the rubber. 
Table 1: Averaged Shore D hardness readings

\begin{tabular}{|l|l|l|}
\hline Region & Region description & Average \\
\hline A1 & Bead (lower) & $\mathbf{2 4 . 4}$ \\
\hline A2 & Bead (upper) & $\mathbf{2 4 . 9}$ \\
\hline S1 & Sidewall (measured inside) & $\mathbf{1 8 . 1}$ \\
\hline S2 & Just below tread (sidewall, outside) & $\mathbf{1 6 . 1}$ \\
\hline T1 & Tread & $\mathbf{3 2 . 0}$ \\
\hline T2 & Side of tread & $\mathbf{1 7 . 5}$ \\
\hline
\end{tabular}

It may be concluded from the results listed in Table 1 that the sidewall of the tyre consists mainly of the same rubber. The bead region is made of harder rubber, but the rubber in the tread region is the hardest. The tyre may therefore be divided into three regions as shown in Figure 3 (right). The tread is considered as one region with homogeneous material properties. The rubber in the sidewall is softer and is considered as a second region. The bead, consisting of a steel rope surrounded by rubber, is defined as the third region. Suitable material properties and models of the three regions had to be determined so as to develop the FE model.

A water-jet cutting machine was used to cut segments out of the tread, sidewall and bead regions of the tyre at the positions shown in Table 2.

Table 2: Material properties obtained for tyre segments

\begin{tabular}{|c|c|c|c|c|c|}
\hline & Bead Region & $\begin{array}{l}\text { Sidewall Region } \\
\text { (Radial) }\end{array}$ & $\begin{array}{l}\text { Sidewall Region } \\
\text { (Circumferential) }\end{array}$ & $\begin{array}{l}\text { Tread Region } \\
\text { (Lateral) }\end{array}$ & $\begin{array}{c}\text { Tread Region } \\
\text { (Longitudinal) }\end{array}$ \\
\hline & 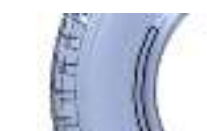 & $x_{5}^{8}$ & ED & wastis & 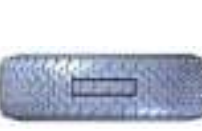 \\
\hline $\begin{array}{l}\text { Young's modulus } \\
\text { (MPa) }\end{array}$ & 13.45 & 490.3 & 4.98 & 335.7 & 432.3 \\
\hline Poisson's ratio & $v_{a-r}=0.12$ & $v_{r-t}=5.05$ & $v_{t-r}=0.13$ & $v_{l a-l o}=0.49$ & $v_{l o-l a}=0.62$ \\
\hline $\begin{array}{l}\text { Material model: } \\
\text { rubber }\end{array}$ & & \multicolumn{2}{|c|}{ Ogden } & \multicolumn{2}{|c|}{ Neo-Hookean } \\
\hline $\begin{array}{l}\text { Material model } \\
\text { parameters }\end{array}$ & & \multicolumn{2}{|c|}{$\begin{array}{c}\mu_{1}=5.037 \mathrm{e}+08 \\
\alpha_{1}=0.00286 \\
\mu_{2}=5.528 \mathrm{e}+08 \\
\alpha_{2}=0.002959\end{array}$} & \multicolumn{2}{|c|}{$\mathrm{C}_{10}=1.803 \mathrm{e}+06$} \\
\hline Quality of fit & & \multicolumn{2}{|c|}{ See Figure 5} & \multicolumn{2}{|c|}{ See Figure 6} \\
\hline Carcass & & $\begin{array}{l}\text { Polyester cords } \\
\text { in radial } \\
\text { direction }\end{array}$ & & $\begin{array}{l}\text { polyester, nylon } \\
\text { and steel cords }\end{array}$ & $\begin{array}{l}\text { polyester, } \\
\text { nylon and } \\
\text { steel cords }\end{array}$ \\
\hline $\begin{array}{l}\text { Material model: } \\
\text { carcass }\end{array}$ & & Orthotropic & & Orthotropic & Orthotropic \\
\hline $\begin{array}{l}\text { Material model } \\
\text { parameters }\end{array}$ & & $\begin{array}{l}\text { Radial: } \\
320 \mathrm{MPa}\end{array}$ & & $\begin{array}{l}\text { Lateral: } \\
200 \mathrm{MPa}\end{array}$ & $\begin{array}{l}\text { Longitudinal: } \\
350 \mathrm{MPa}\end{array}$ \\
\hline
\end{tabular}


An EZ50 $(50 \mathrm{kN})$ Universal Materials Testing Machine was used for performing the tensile tests on the test specimens as indicated in Figure 4 and for recording the forces applied to the samples. As the samples were axially extended, they became thinner owing to the Poisson effect. The lateral and longitudinal deformations were both measured by applying six small dots of white paint in a rectangular pattern onto the specimen's surface. During testing, photographs were taken of the specimens at various tensile loads and the surface strains determined by processing the images in Matlab. This enabled the compilation of non-linear stress-strain data for the test samples.

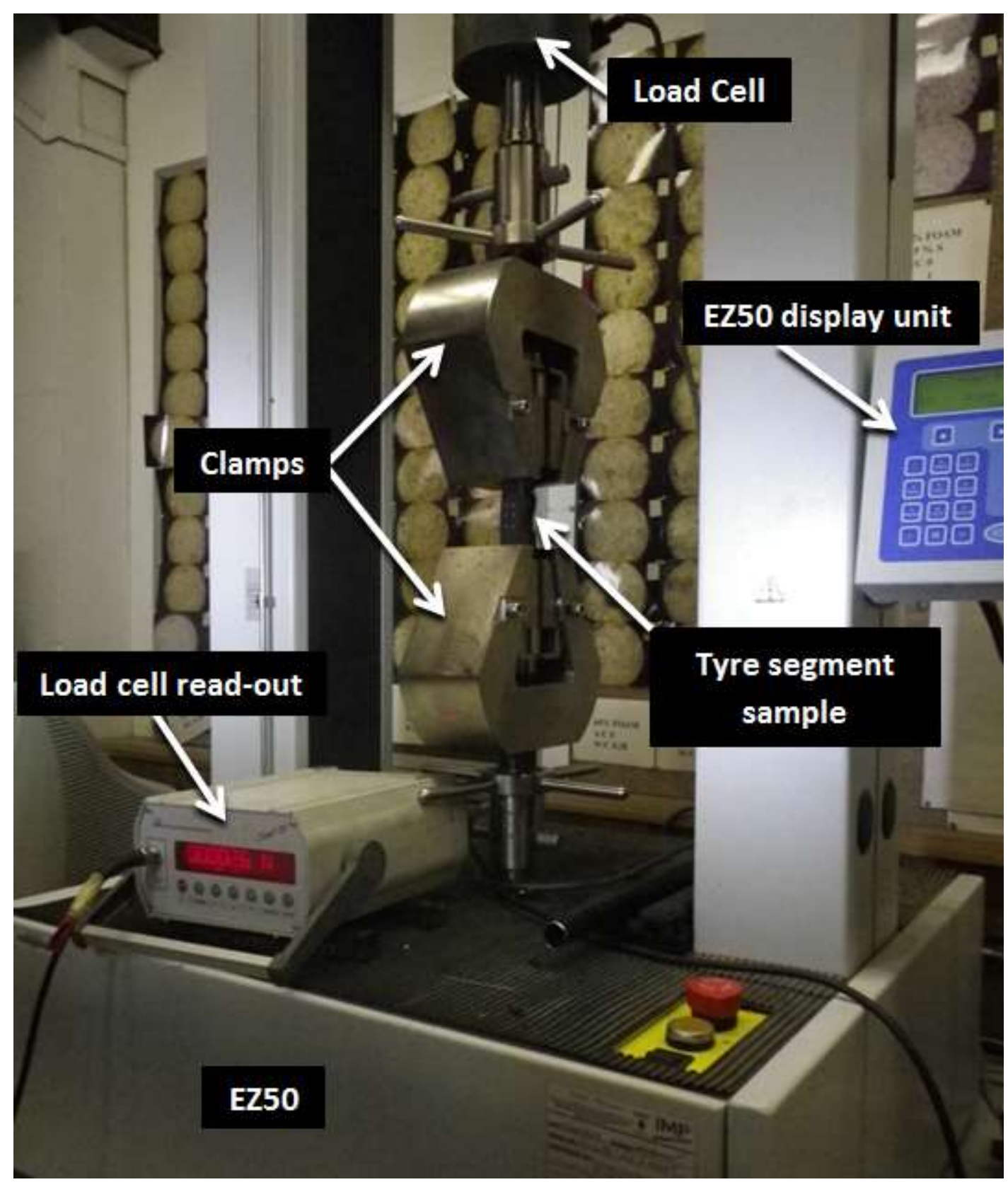

Figure 4: Tension test experimental setup

Young's moduli for rubbers used in tyres are typically between 0.77 and $7 \mathrm{MPa}[28,29,30]$. Young's Moduli and Poisson's ratios, determined for the different regions of the tyre, are shown in Table 2. The Young's modulus in the circumferential direction was measured as $4.98 \mathrm{MPa}$ in the sidewall and as $13.45 \mathrm{MPa}$ in the bead region. 
These values mainly represent rubber stiffness, because no threads/wires are aligned to the circumferential direction. The material for both the tread and the sidewall is anisotropic, since Poisson ratios larger than 0.5 were measured. The reciprocity relations (Equations. 4, 5 and 6) are valid for the relationship between the radial and circumferential values for the sidewall and for the relationship between the lateral and longitudinal values for the tread. The large differences in the Young's Moduli can be explained by the direction of the plies embedded in the rubber in the tyre.

The sidewall of the tyre contains polyester threads which are aligned radially. As expected, the measured stiffness is much larger in the radial direction than in the circumferential direction. To account for this anisotropy, the sidewall was modelled as two layers of superimposed elements, namely a rubber layer and a carcass layer, each with different material properties. The material model for the rubber layer was obtained from the tensile tests in the circumferential direction (perpendicular to the direction of the carcass) and represents the rubber only. An acceptable experimental data fit for an Ogden model was obtained by using MSC Marc (shown in Figure 5). The model's parameters are indicated in Table 2. The carcass layer was modelled as an orthotropic material with a Young's Modulus of $320 \mathrm{MPa}$ in the radial direction. No stiffness was added in the other two orthogonal directions.

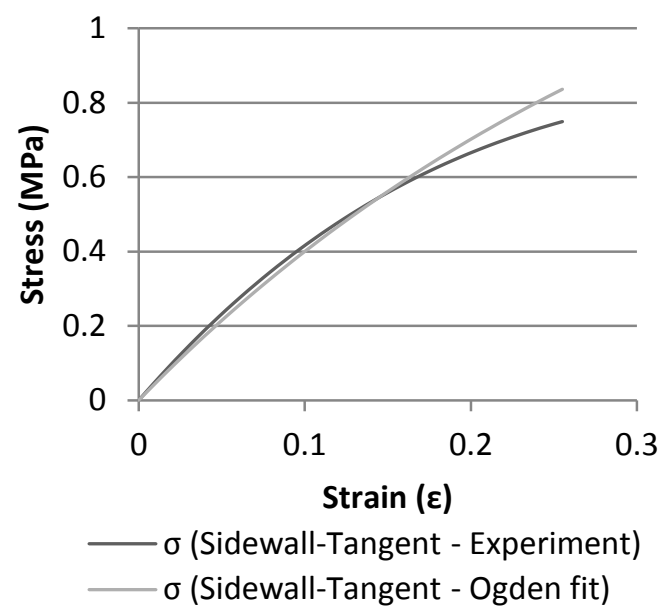

Figure 5: Ogden experimental data fit for sidewall rubber

The rubber in the tread of the tyre is harder than the rubber in the sidewall, as shown in Table 1. Since no tests could be done on the tread in the radial direction (because of the geometry), the experimental stress-strain values from the tests on the bead region were used. The bead region also consists of a harder rubber, similar to the rubber in the tread region. A Neo-Hookean model with $\mathrm{C}_{10}=1.803 \mathrm{e}+06$ was used for the elements simulating the rubber in the model (shown in Figure 6).

Superimposed orthogonal elements were used to compensate for the extra stiffness in the lateral and longitudinal directions. The orthogonal material properties of these elements were set up with a Young's Modulus of 200 $\mathrm{MPa}$ in the lateral direction and $350 \mathrm{MPa}$ in the longitudinal direction. No stiffness was added in the radial direction, since none of the embedded wires or cords was aligned radially in the tread region. 


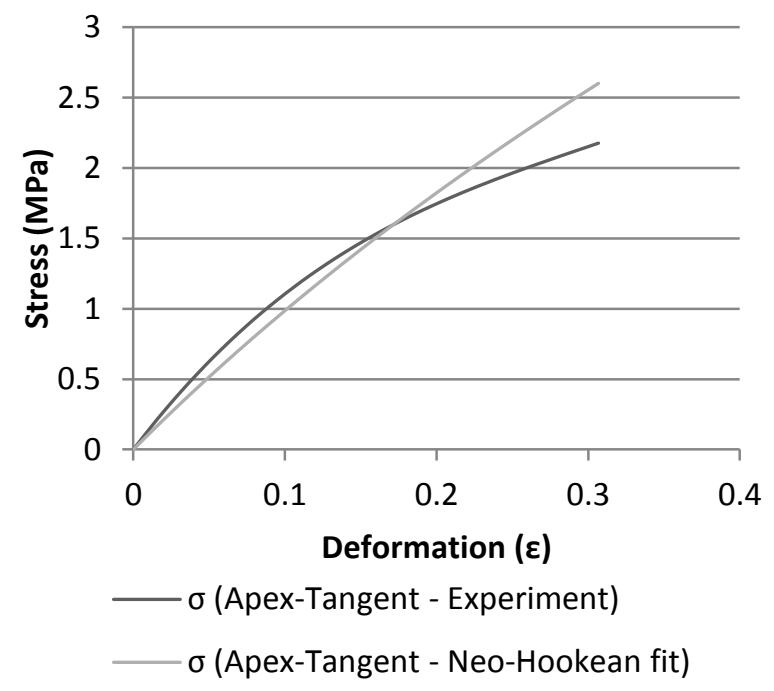

Figure 6: Neo-Hookean experimental data fit for tread rubber

\subsection{Cleat tests}

Radial force vs. displacement, as well as sidewall deformation profiles, were measured by using the test setup depicted in Figure 7 and Figure 8 at a tyre inflation pressure of $200 \mathrm{kPa}$. The tyre was slowly compressed from the undeflected position and then was returned to the initial position, using a servo-hydraulic actuator. Tests were performed using a flat plate, and lateral and longitudinal square cleats (19, 25, 38, 51 and 76 mm) as well as a $100 \mathrm{~mm} \times 50 \mathrm{~mm}$ rectangular cleat. Displacement of the flat plate as well as deformation of the tyre at the cleat position was measured using laser displacement transducers. Figure 9 indicates the measured forcedisplacement obtained for the flat plate and the lateral cleats. Figure 9 indicates a reduction in force over the cleats compared to the flat plate and also a slight hysteresis loop. Using the same experimental setup, with the same cleats, the tyre sidewall profiles were measured at the centre of indentation at different loading conditions, using two laser displacement transducers (also shown in Figure 8). These results were compared to the finite element results to validate the model.

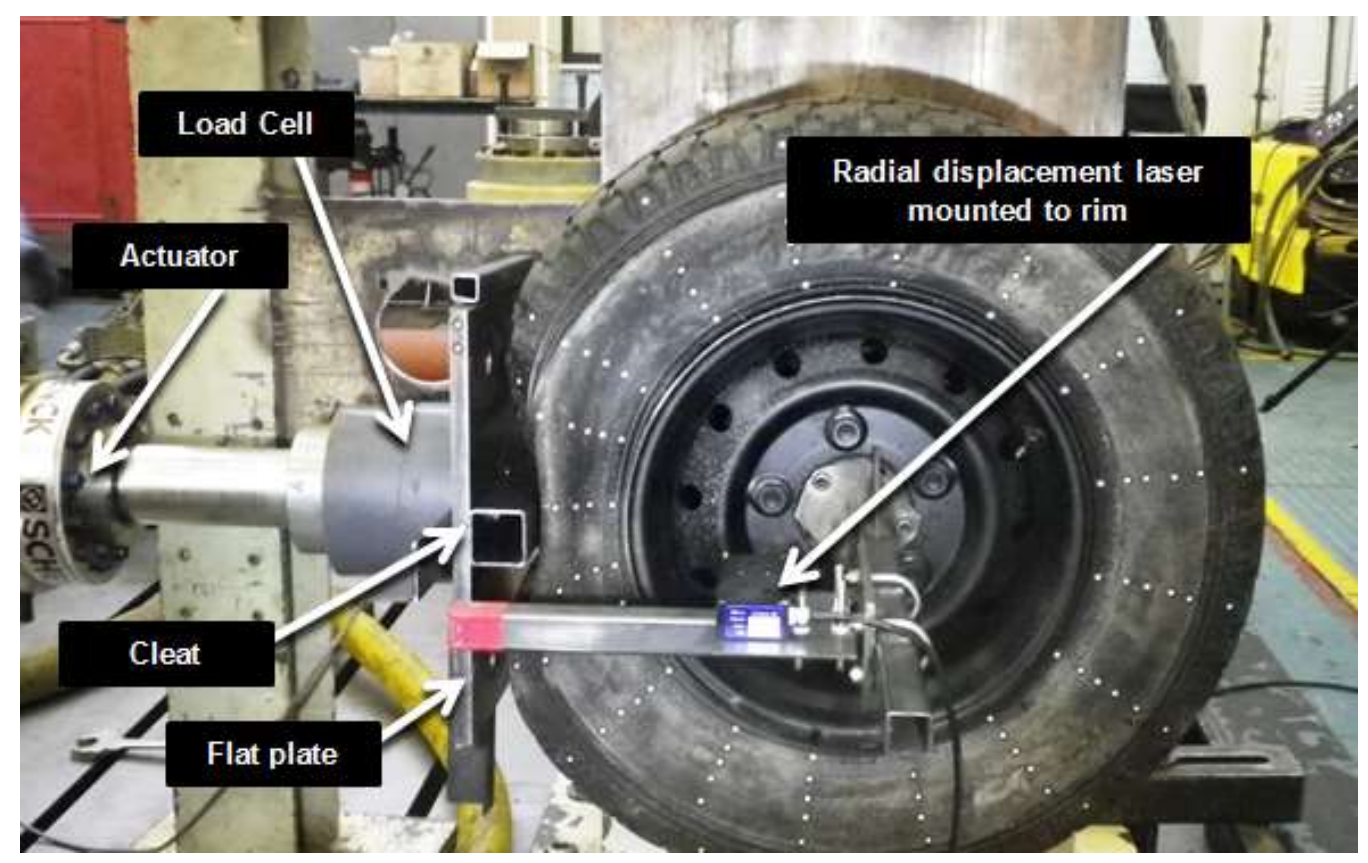

Figure 7: Load vs. displacement measurement 


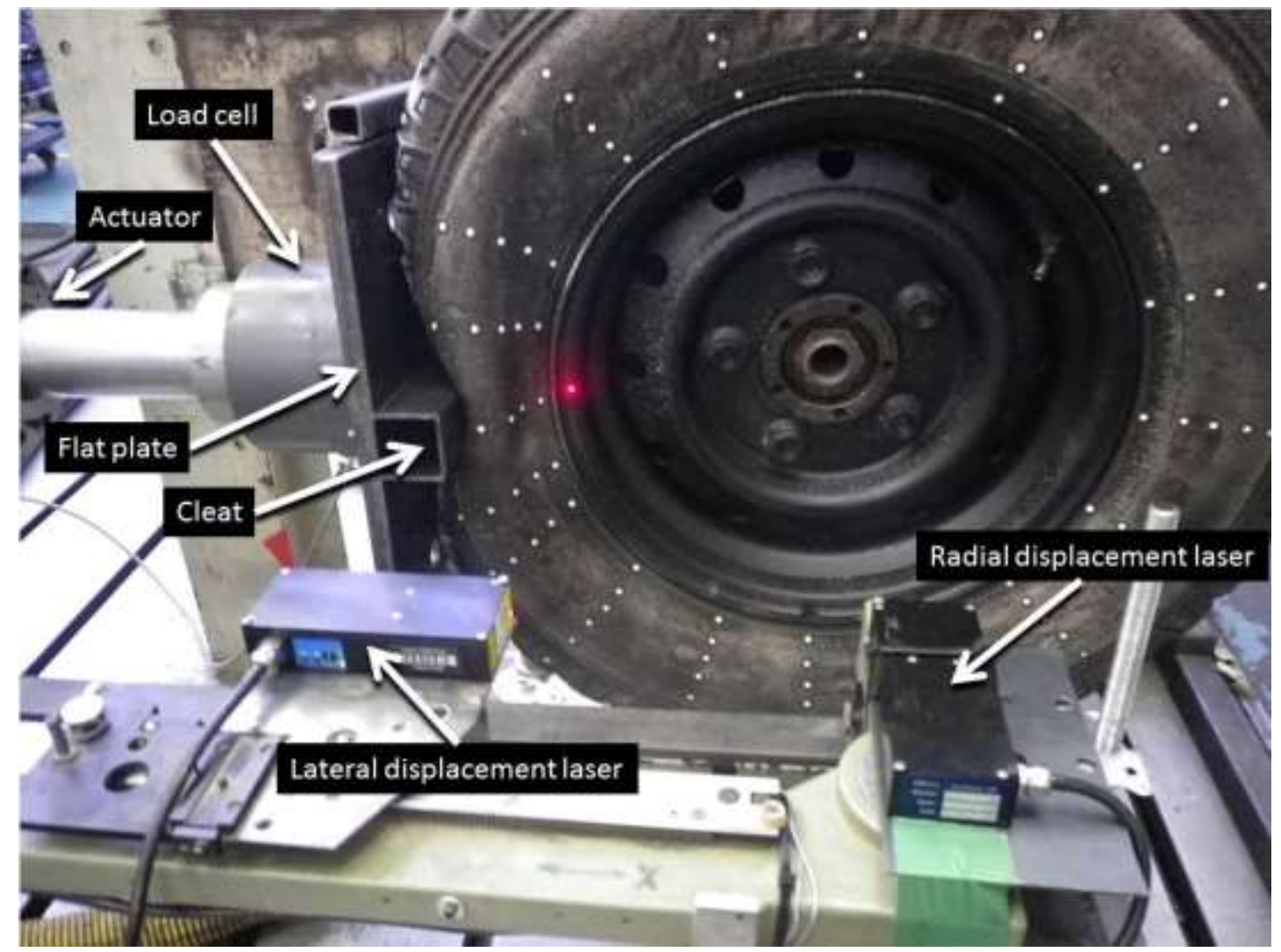

Figure 8: Sidewall deformation measurement

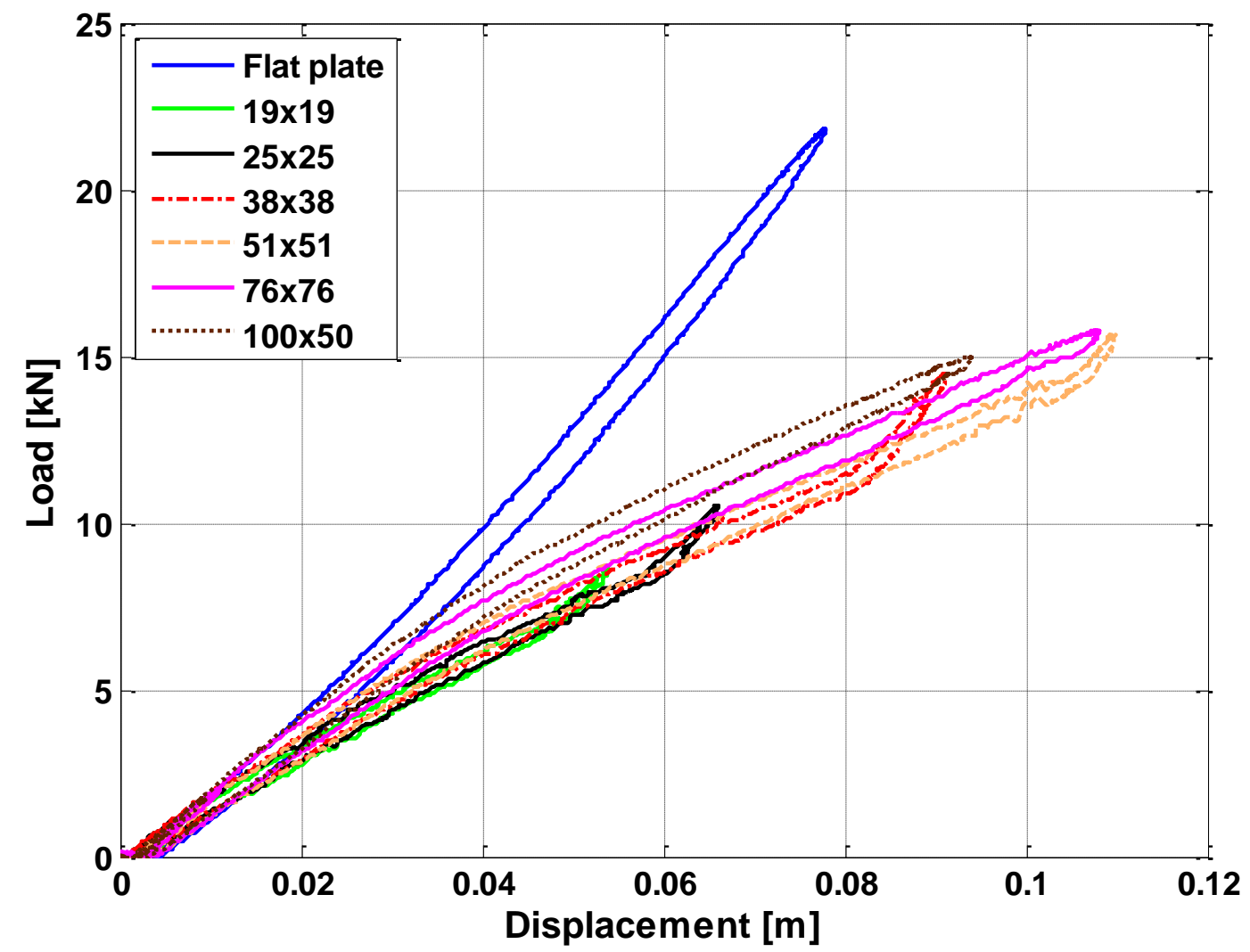

Figure 9: Radial tyre stiffness for flat surface and lateral cleats at $200 \mathrm{kPa}$ 


\section{Finite element model of tyre}

The finite element model was developed in steps of increasing complexity. First the test samples were modelled and the results compared to the material characterization tests. Then a two-dimensional model was developed and subjected to the inflation pressure. Finally the model was expanded to three dimensions.

\subsection{FE models of samples}

In order to verify whether or not the material properties, obtained from the experiments described in Section 2.2 and summarised in Table 2, could be successfully incorporated in the FE model, the tensile tests were replicated in simulation, using the MSC Marc FE code [27]. The samples were modelled by using 8-noded hexahedral (cubic) elements, as is the case for most of the detailed finite element models of tyres in recent literature [31, 4, $32,33,34,35,6]$. In order to compensate for the different stiffnesses caused by the steel wires, polyester and nylon threads between the rubber in the carcass and tread of the tyre, non-linear anisotropic elements and linear orthotropic elements were combined with each other. A typical FE model for one of the samples is shown in Figure 10. The model is restrained at the clamped end. A force is then applied to a rigid multi-point constraint on the other end, which distributes the force evenly to the symmetry face.

Figure 11 compares the FE model results to the experimental results for a sidewall specimen. Comparisons for the lateral and longitudinal tread specimens are shown in Figure 12 and 13. The material properties correlate reasonably well with the experimental values obtained from the tensile tests, although the non-linearities are not captured accurately. Since orthotropic elements are limited to linear stiffnesses, it was deemed acceptable to extend the analysis to a two-dimensional model because the Young's modulus of the rubber is far lower than that of the carcass material, as can be seen from Table 2 .

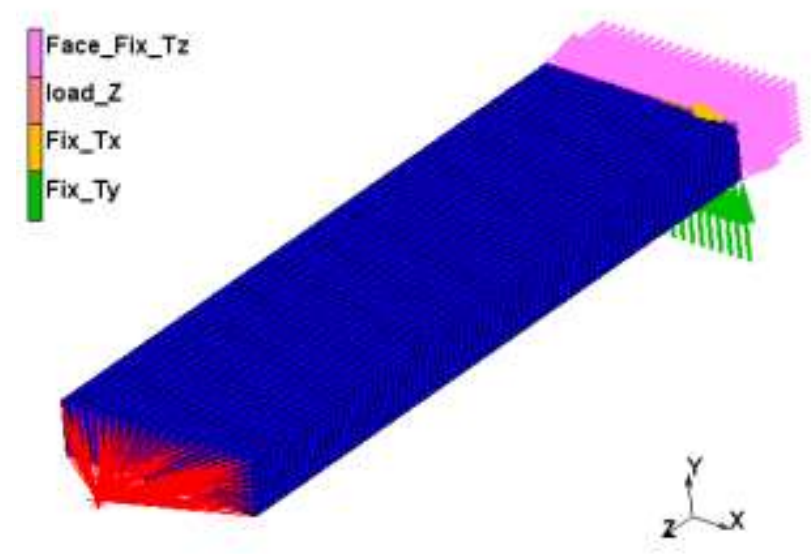

Figure 10: Example of a tyre sample analysed 


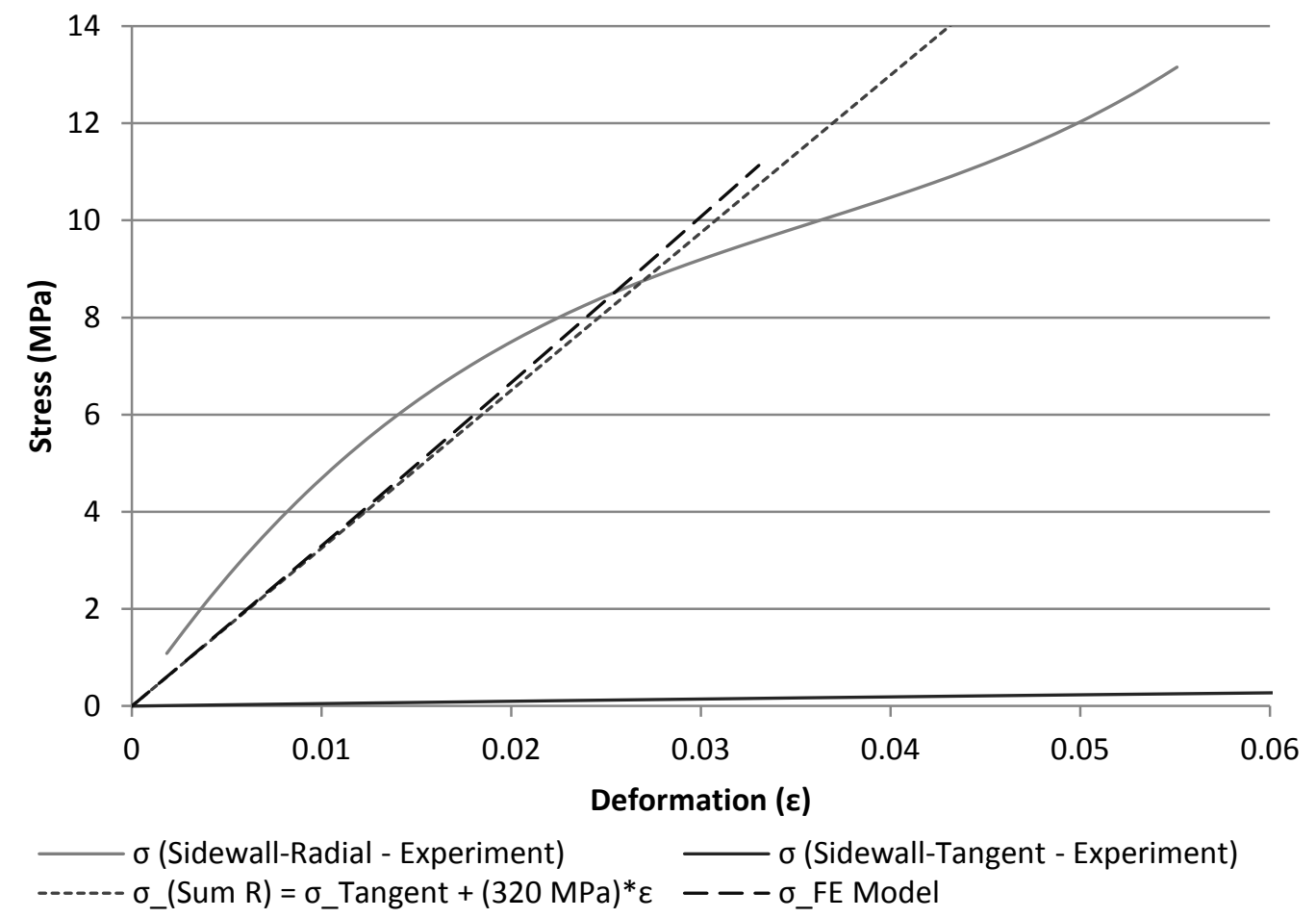

Figure 11: Sidewall material correlation in the radial direction

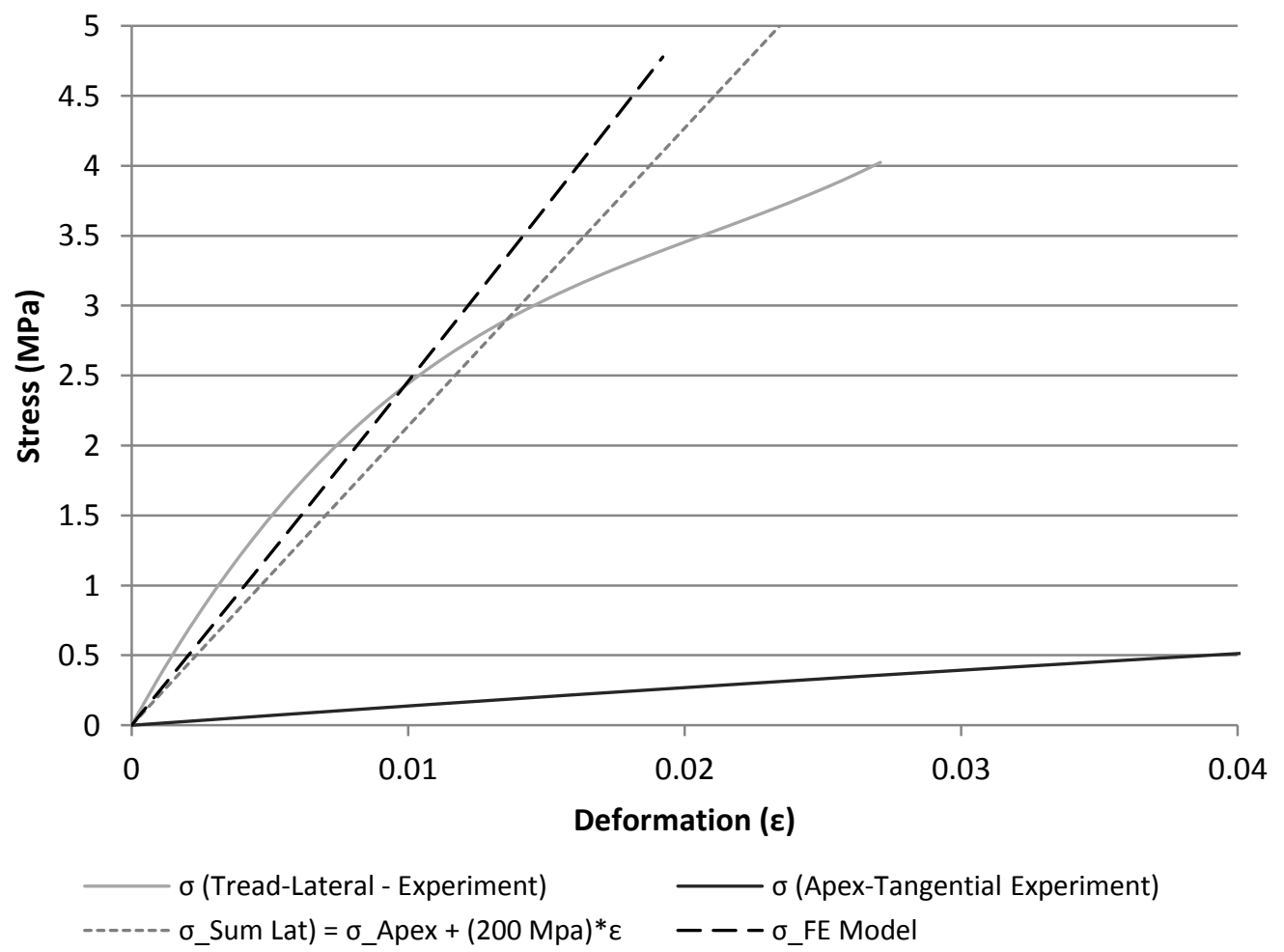

Figure 12: Tread material correlation in the lateral direction 


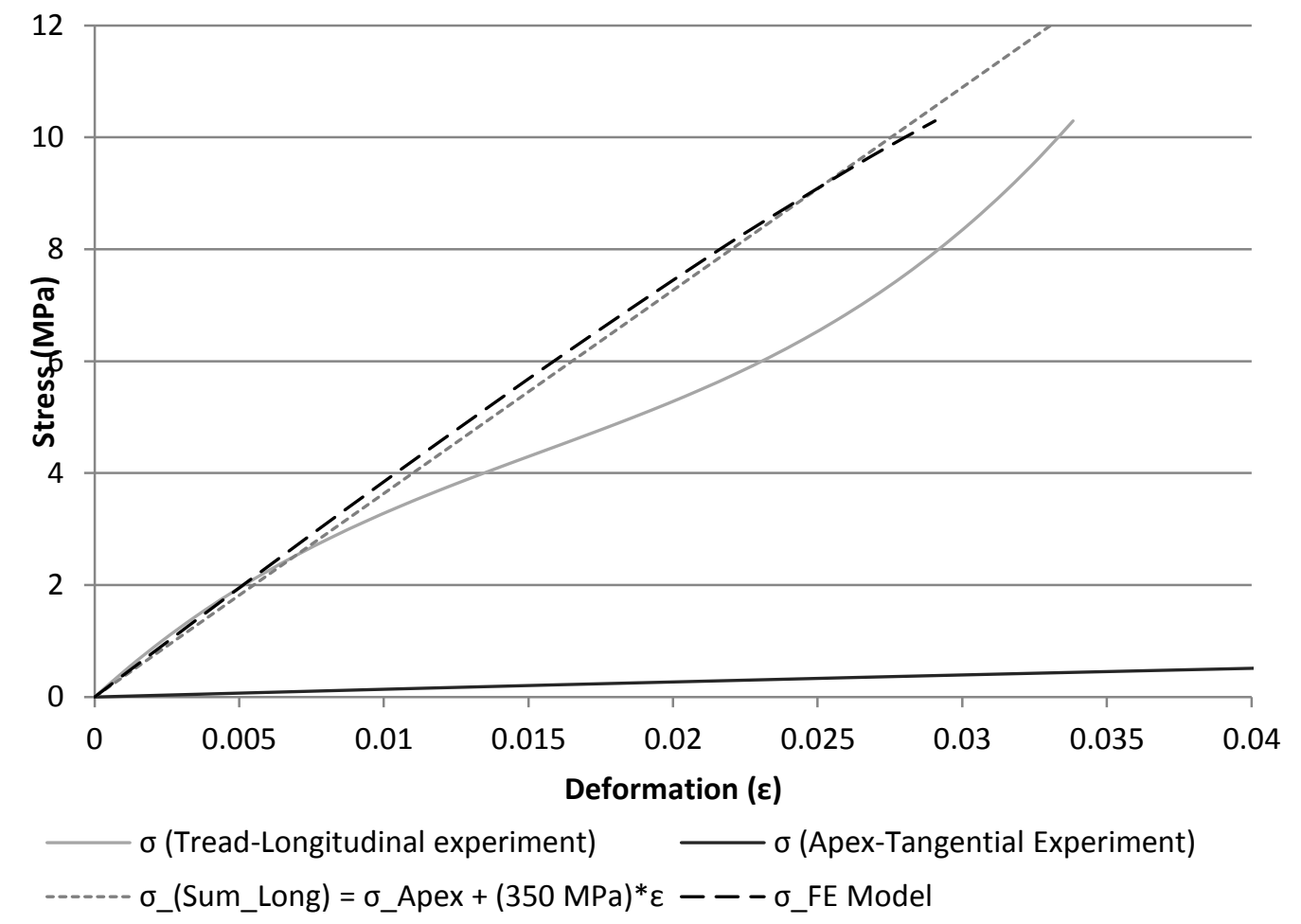

Figure 13: Tread material correlation in the longitudinal direction

\subsection{Two-dimensional model}

A two-dimensional model of the tyre (cross-section) was developed to determine whether the material properties used in the models of the test samples would give a similar tyre sidewall profile when applying an inflation pressure of $200 \mathrm{kPa}$ in the FE model. The orientations of the elements were aligned with the profile of the tyre, as shown in Figure 14, in order to align the orthogonal material properties accordingly. The tyre is defined as a deformable body in the model, whereas the curves representing the rim are defined as a rigid body. The model is constrained from moving horizontally at the nodes aligned with the centreline of the tyre for the inflation analysis. A pressure of $200 \mathrm{kPa}$ was applied to the inside of the tyre (as shown in Figure 15 left) and the displacement upon full inflation is shown in Figure 15 (right).
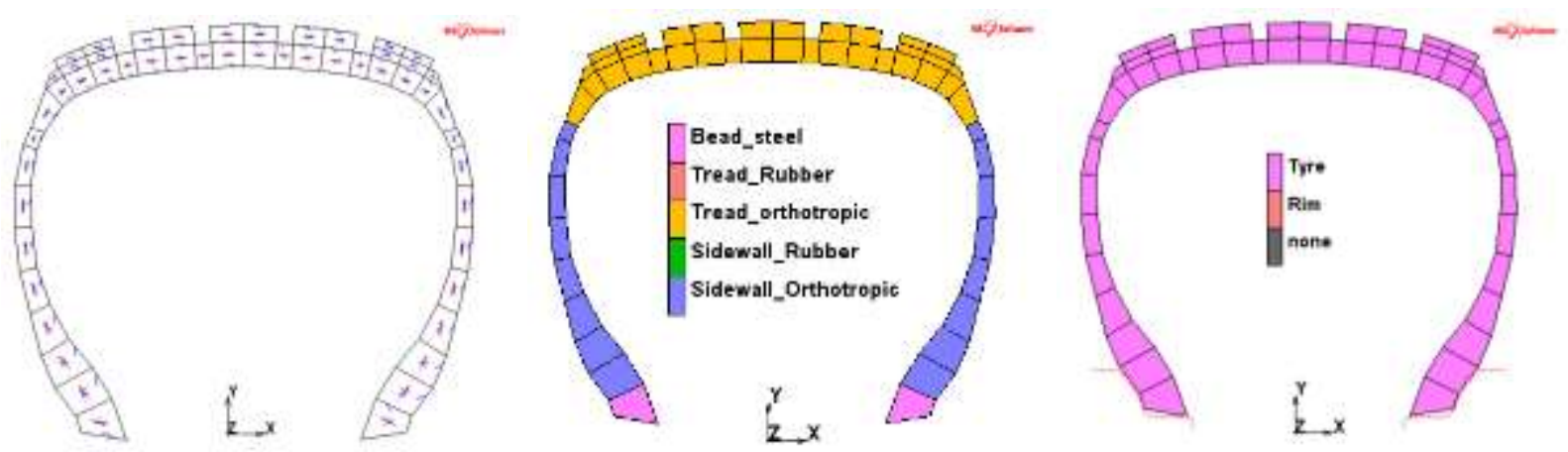

Figure 14: Orientation of elements (left), segments (middle) and contact (right) for 2-D axisymmetric model 

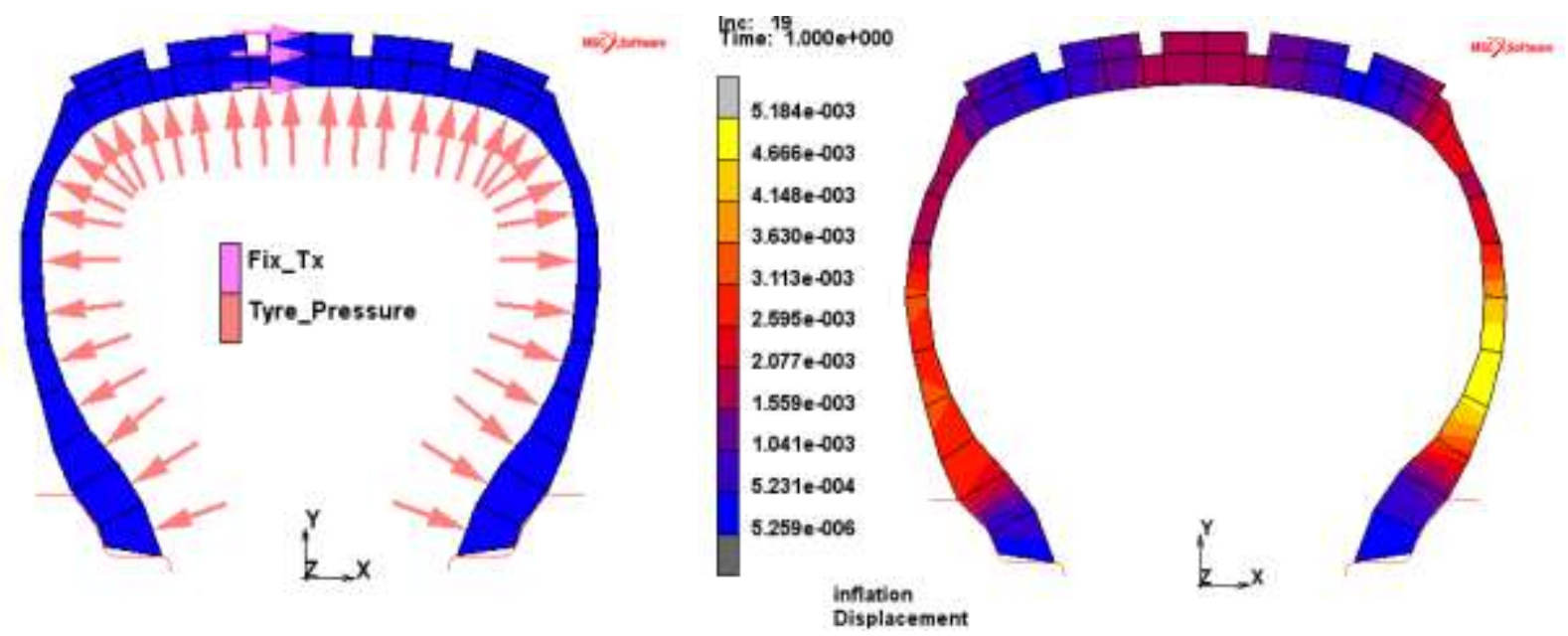

Figure 15: Pressure applied to inside of the tyre (left) and displacement of 2-D model to $200 \mathrm{kPa}$ (right)

\subsection{Three-dimensional model}

The non-linear material properties and the orthogonal properties in the three-dimensional model are both transferred around the centre axis when the two-dimensional model is revolved. The sizes of the elements around the contact patch are made three times smaller than the rest of the elements in the tyre, since this is the region where large deformation is expected. The number of elements in each region of the three-dimensional tyre is indicated in Table 3 below.

Table 3: Elements used in the 3-D model

\begin{tabular}{|l|l|l|r|}
\hline Region & Material type & Element type & Number of elements \\
\hline Bead & Isotropic & Hex8 & 84 \\
\hline Tread & Neo-Hookean & Hex8 & 1428 \\
\hline Tread & Orthotropic & Hex8 & 1428 \\
\hline Sidewall & Ogden & Hex8 & 672 \\
\hline Sidewall & Orthotropic & Hex8 & 672 \\
\hline Total & & & $\mathbf{4 2 8 2}$ \\
\hline
\end{tabular}

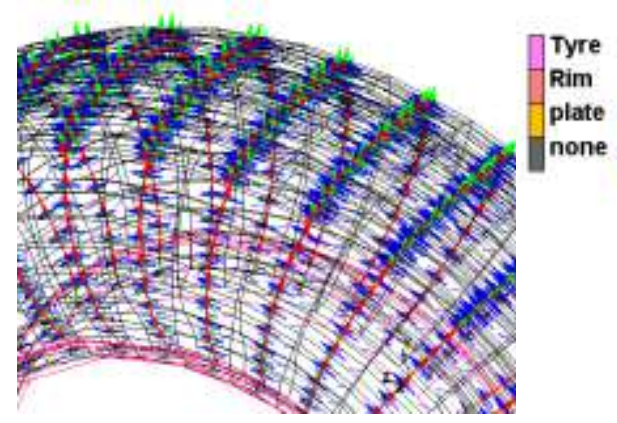

Figure 16: Orientation of elements (left), contact bodies (middle) and inflation pressure applied to inside of tyr (right) for the 3-D model

The orientation of elements in the three-dimensional model is shown in Figure 16 (left). In the three-dimensional model, the plate (or plate with cleat) used in the experimental tests is modelled as a rigid body (Figure 16, middle). The plate is given a constant velocity towards the tyre as input to simulate the movement of the actuator pushing the plate against the tyre. The contact between the rim and the tyre is defined as a "glued" connection in a contact table used by MSC Mentat. (This contact constraint prevents nodes from penetrating, separating or 
sliding relative to the curves that represent the rim.) The contact between the tyre and the plate and the contact of the tyre with itself are defined as "touching". The fixed restraint in the middle of the tyre, used for the twodimensional model, was removed for the three-dimensional model. The tyre pressure of $200 \mathrm{kPa}$ is applied to the inside faces of the elements in the model (see Figure 16, right).

\section{Correlation of FE tyre model with experimental results}

In the FE analyses, the flat plate (with cleats) was moved radially towards the inflated tyre while the rim was fixed in space. Force-displacement curves and sidewall profiles were generated from the analysis for direct comparison with the experimental results described in paragraph 2.3. The force vs. displacement curves are shown in Figure 17 for a flat surface (left), for a $25 \times 25$ lateral cleat (middle) and a $25 \times 25$ longitudinal cleat (right). The material properties in Table 2 were used first. The force vs. displacement graphs obtained with these values are labelled "default values". Variations in sidewall radial stiffness, tread longitudinal stiffness and tread lateral stiffness were investigated on a trial-and-error basis by changing the respective orthogonal stiffnesses. The parameters giving the best results are indicated as "FE final values" in Figure 17 and compared to the default values in Table 4.

Figure 17 (left) illustrates an excellent correlation between the measured and simulated values when compressing the tyre on a flat surface. The results are also insensitive to changes in material parameters. Figure 17 (middle) indicates a good correlation up to a displacement of $30 \mathrm{~mm}$. The model captures the kink in the graph but this occurs at higher displacements than the experimental values and the forces are about $20 \%$ higher. Tweaking the material model parameters led to some improvement in the force, but the position of the transition remained unchanged. This points to some discrepancy in the parameters, which does not depend on the material properties. The discrepancy is probably caused by inconsistent geometry or the glued contact specified between the tyre and the rim. The glued contact prevents the tyre from losing contact at the very bottom of the tyre once it has touched the rim. The results over the longitudinal cleat (Figure 17, right) are excellent and are improved by tweaking the material parameters. Figure 18 indicates similar trends over a very large cleat.
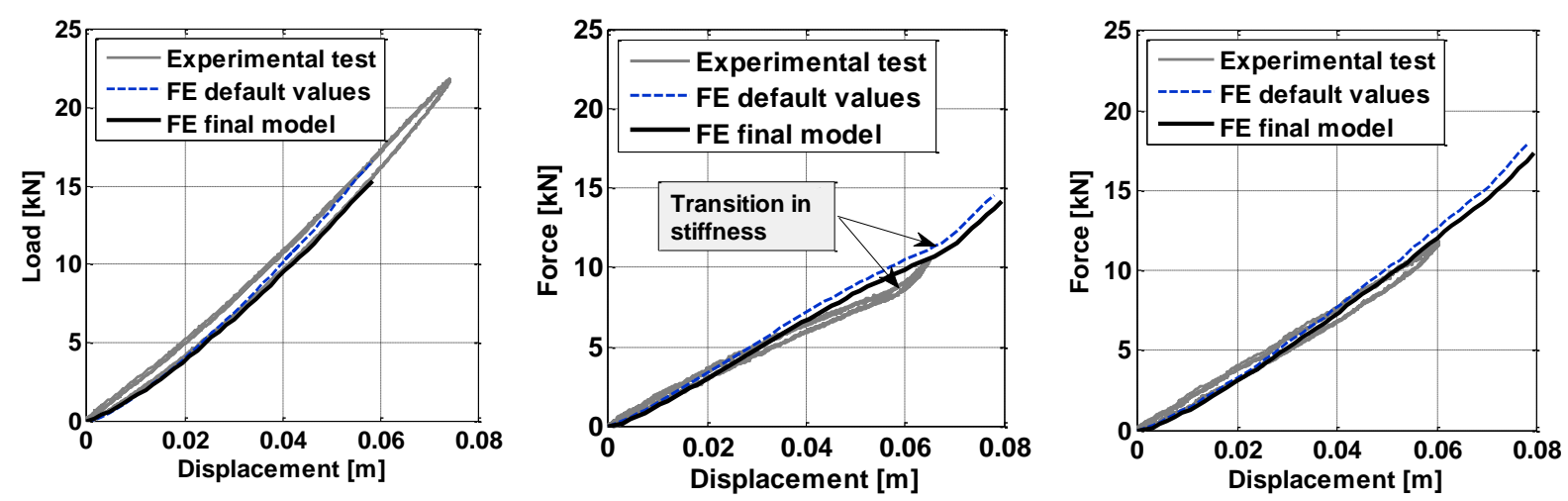

Figure 17: Radial force vs. displacement with flat surface (left), $25 \times 25$ lateral cleat (middle) and $25 \times 25$ longitudinal cleat (right) 

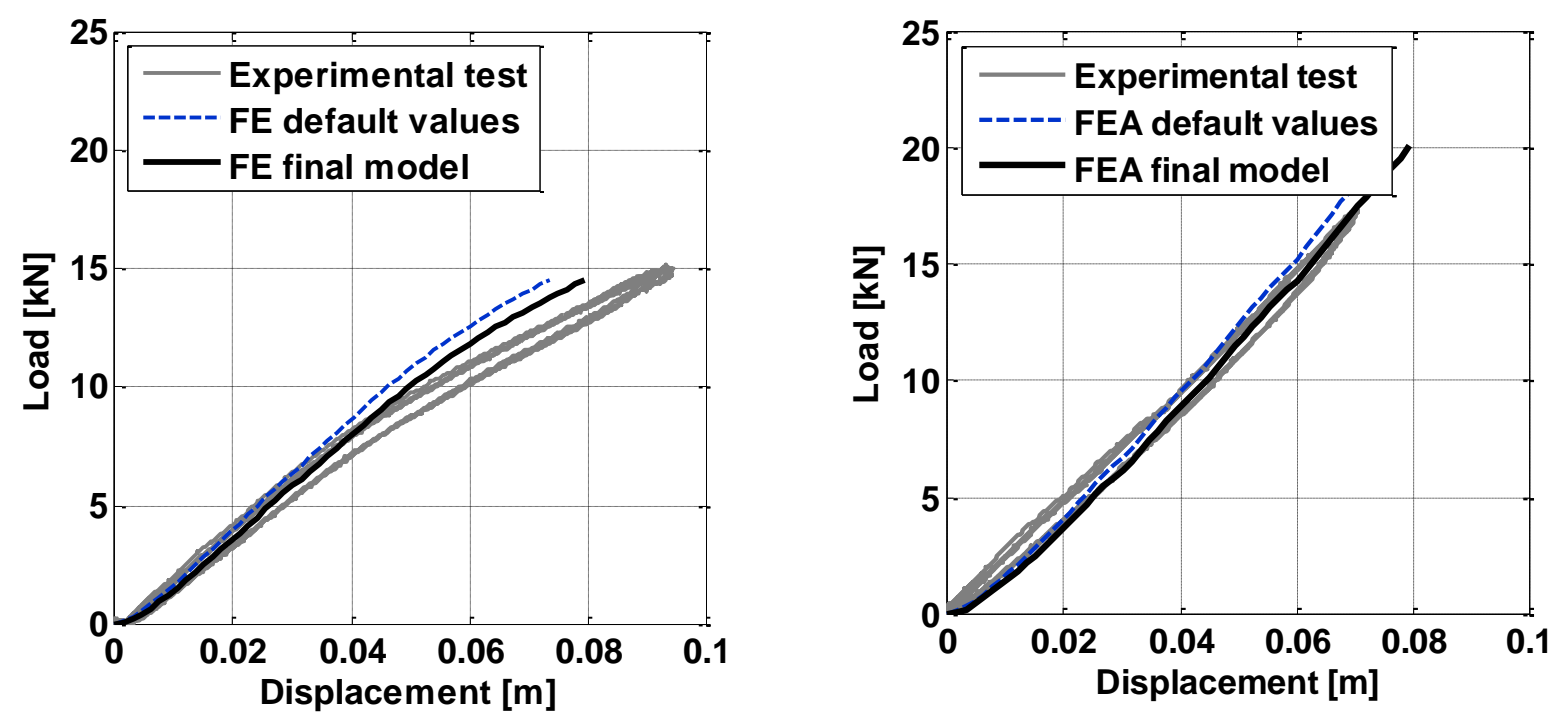

Figure 18: Radial force vs. displacement for $100 \times 50$ lateral cleat (left) and $100 \times 50$ longitudinal cleat (right)

Table 4: Material properties for final FE model of tyre

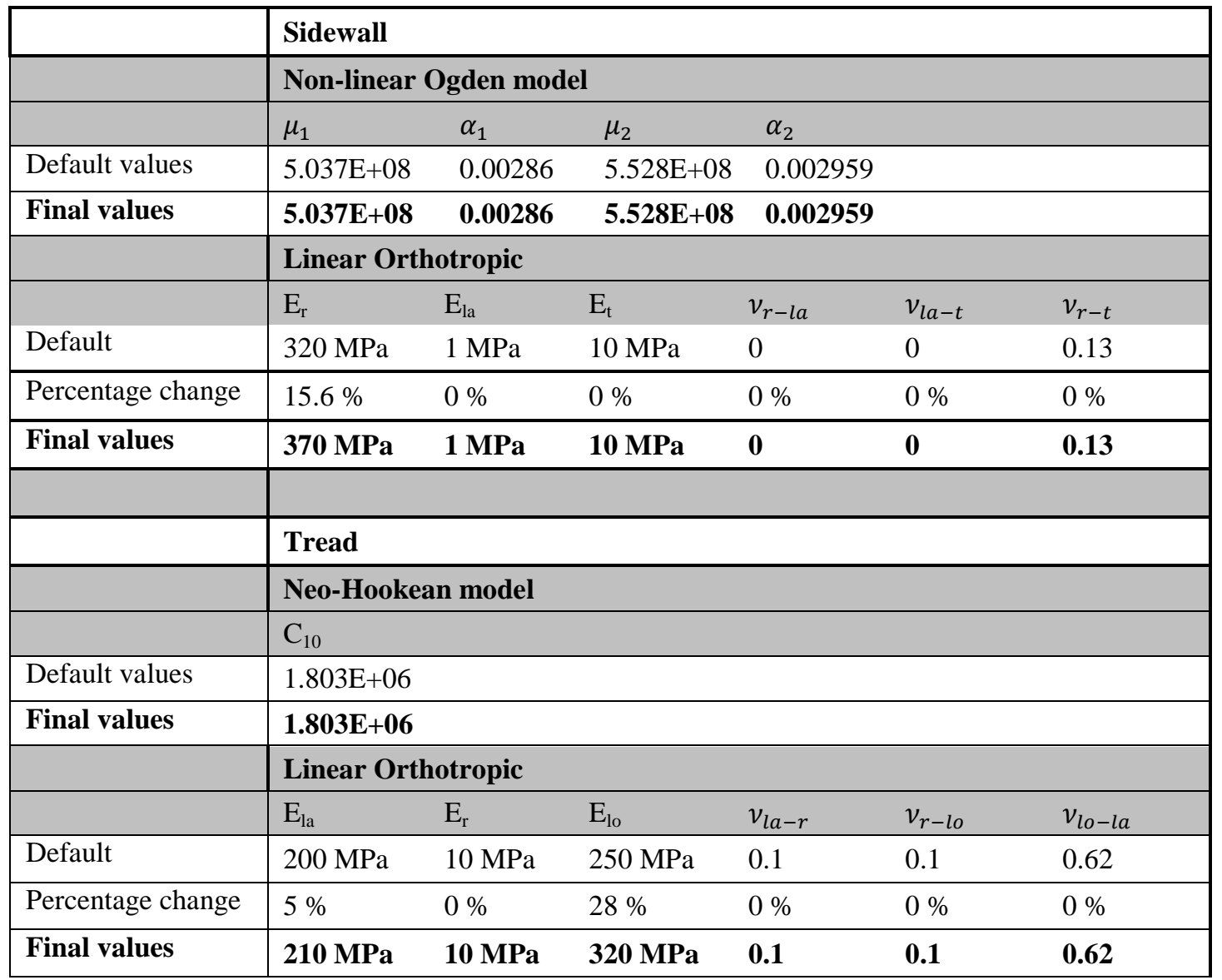

The deformation profiles of the sidewall at the different loads (no load, $5 \mathrm{kN}, 10 \mathrm{kN}, 15 \mathrm{kN}$ ) are compared to the experimental measurements in Figure 19 for the flat surface (left) and the large longitudinal cleat (right). The displacement profiles of the sidewall of the final model are a good match to the experimental profiles. Since the approach followed in this paper was only tested on a flat plate with cleats, the applicability thereof on real deformable surfaces should be investigated in further research studies. 

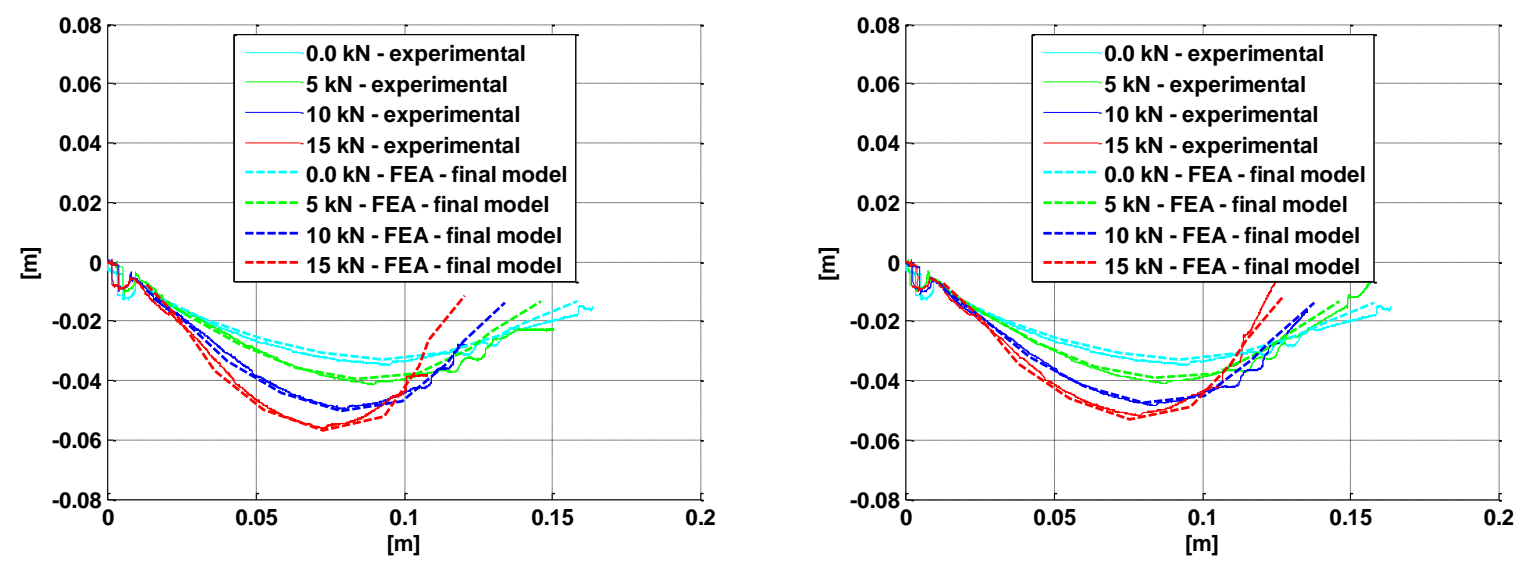

Figure 19: Sidewall profiles for flat surface (left) and for $100 \times 50$ longitudinal cleat (right)

\section{Conclusions}

The purpose of this paper was to investigate the possibility of using a course finite element model, using the bulk material properties determined from tensile tests on specimens cut from different positions on a tyre, to predict the force-displacement characteristics on a flat surface and on cleats accurately enough to be useful for tyre model parameterization. Although the concept was proven on a light truck's off-road tyre, the real application is for very large tyres where testing the full tyre is not feasible or prohibitively expensive.

Test samples were cut at various orientations from the tread and sidewall of a tyre, using a water-jet cutter. Stress-strain relationships were determined by using tensile testing. Strain was measured by analysing the images from a digital camera to track markers on the test specimens. Non-linear anisotropic material models were parameterized and elements, with different material properties in various directions, were superimposed to mimic the properties of the tyre rubber and carcass.

Simple FE models of the samples were built to determine the merit of superelements to simulate different material properties in the three different orthogonal directions for the tread and for the sidewall of the tyre. These models were extended to a two-dimensional model to verify the effect of adding inflation pressure inside the tyre and subsequently a full three-dimensional model was developed.

The global behaviour of the FE model was analyzed by comparing the experimental and simulation data on a flat surface as well as on various lateral and longitudinal cleats. The results indicate that the FE model can predict with acceptable accuracy the vertical force vs. displacement, as well as the sidewall deformation of the tyre under static loading conditions on a flat surface and on various different cleats by using the equivalent (global) material properties obtained from tensile testing.

The model developed can be used to investigate the effect of different stiffnesses and other material changes in the sidewall or tread of a tyre. The technique is accurate enough to be used in the parameterization of various tyre models where the force vs. global displacement data is important. 


\section{Bibliography}

[1] H. R. Ghoreishy, "A State of the Art Review of the Finite Element Modelling of Rolling Tyres," Iranian Polymer Journal, vol. 17, no. 8, pp. 571-597, 2008.

[2] A. Mohsenimanesh, S. Ward and M. Gilchrist, "Stress analysis of a multi-laminated tractor tyre using nonlinear 3D finite element analysis," Materials and Design, vol. 30, no. 4, pp. 1124-1132, 2009.

[3] I. Darnell, G. M. Hulbert and C. W. Mousseau, "An efficient three-dimensional tire model for vehicle dynamics simulations," Mechanics of Structures and Machines, vol. 25, no. 1, pp. 1-19, 1997.

[4] E. Tönük and Y. Ünlüsoy, "Prediction of automobile tire cornering force characteristics by finite element modeling and analysis," Computers \& Structures, vol. 79, no. 13, pp. 1219-1232, 2001.

[5] N. Korunovic, M. Trajanovic and M. Stojkovic, "Finite Element Model for Steady-State Rolling Tire Analysis," Journal of the Serbian Society for Computational Mechanics, vol. 2, no. 1, pp. 63-79, 2008.

[6] M. H. R. Ghoreishy, "Finite Element Modelling of the Steady Rolling of a Tyre with Detailed Tread Pattern," Iranian Polymer journal, vol. 18, no. 8, pp. 641-650, 2009.

[7] P. Kindt, P. Sas and W. Desmet, "Three-dimensional Ring Model for the Prediction of the Tyre Dynamic Behaviour," Proceedings of ISMA, pp. 4155-4170, 2008.

[8] J. Cho, J. Choi and Y. Kim, "Abrasive wear amount estimate for 3D patterned tire utilizing frictional dynamic rolling analysis," Tribology International, vol. 44, pp. 850-858, 2011.

[9] Y. Cai, M. Zang, Y. Chen and W. Liu, "Experiments and finite element simulations of a tyre blow-out process," Proceedings of the Institution of Mechanical Engineers, Part D: Journal of Automobile Engineering, 2014.

[10] M. Stallmann and P. Els, "Parameterization and Modelling of Large Off-Road Tyres for Ride Analyses: Part 2 - Parameterization and Validation of Tyre Models," Journal of Terramechanics, vol. 55, pp. 85-94, 2014.

[11] H. Sugiyama and Y. Suda, "Non-linear elastic tyre model using the absolute nodal coordinate formulation," Journal of Multi-body dynamics, pp. 211-219, 2009.

[12] I. Besselink, "Vehicle dynamics analysis using SimMechanics and TNO Delft-Tyre," 2006.

[13] MF-Tyre, “MF-Tyre \& MF-Swift 6.1 User Manual,” http://www.delft-tyre.nl/, 2008.

[14] H. B. Pacejka, Tyre and Vehicle Dynamics, Second ed., Elsevier Science Technology, 2006.

[15] J. Badalamenti and G. Doyle, "Radial-interradial spring tire models," Journal of vibration, accoustic, stress and reliability in desing, vol. 110, no. 1, pp. 70-75, 1988.

[16] M. Gipser, "FTire, a New Fast Model for Ride Comfort Simulations," in International ADAMS User's Conference, Berlin, Germany, 1999.

[17] P. Witzel, S. Böttinger and H. D. Kutzbach, "The Advanced Hohenheim Tyre Model for the Simulation of Obstacle Passages," in Proceedings of the 18th International Conference of the International Society for Terrain-Vehicle Systems, Seoul, Korea, 2014.

[18] C. Oertel and A. Fandre, "Ride comfort simulations and steps towards life time calculations: RMOD-K and ADAMS," 1999.

[19] RMOD-K, "RMOD-K 7," 2011. [Online]. Available: http://rmodk.com/index.php?option=com_content\&view=article \&id=49:flexiblebelt\&catid=24:flexiblebelt\&Itemid=79. [Accessed 2011].

[20] M. Gipser, "ADAMS/FTire - A Tire Model for Ride \& Durability Simulations," in ADAMS User's Conference, Tokyo, 2000. 
[21] C. F. Zorofski, "Mathematical Prediction of Dynamic tire Behavior," Tire Science and Technology, vol. 1, pp. 99-117, 1973.

[22] J. R. Cho, K. W. Kim, W. S. Yoo and S. I. Hong, "Mesh generation considering detailed tread blocks for reliable 3D tire analysis," Advances in Engineering Software, vol. 35, pp. 105-113, 2004.

[23] K. Xia, "Finite element modeling of tire/terrain interaction: Application to predicting soil compaction and tire mobility," Journal of Terramechanics, vol. 48, pp. 113-123, 2011.

[24] ANSYS, ANSYS Theory Manual 2007 Version 11, USA: ANSYS Inc., 2007.

[25] G. Z. Voyyiadjis and P. I. Kattan, Mechanics of Composite Materials with MATLAB, New York: Springer Berlin Heidelberg, 2005.

[26] M. Sasso, G. Palmieri, G. Chiappini and D. Amodio, "Characterization of hyperelastic rubber-like materials by biaxial and uniaxial stretching tests based on optical methods," Polymer Testing, vol. 27, pp. 995-1004, 2008.

[27] J. Oden and Y. Fung, "Nonlinear Finite Element Analysis of Elastomers - White Paper, MSC Software," MSC Software, 2010. [Online].

[28] T. Edeskär, "Technical and environmental properties of tyre shreds focussing on ground engineering applications,” Luleå University of Technology, Luleå, 2004.

[29] F. Koutný, “Geometry and mechanics of pneumatic tires,” Koutny-Math, Zlín, 2007.

[30] A. Drescher, D. Newcomb and T. Heimdahl, "Deformability of shredded tires," Minnesota Department of Transportation, Minnesota, 1999.

[31] H. Nakashima and J. Wong, "A three-dimensional tire model by the Finite Element Method," Journal of Terramechanics, 1993.

[32] X. Yan, Y. Wang and X. Feng, "Study for the endurance of radial truck tires with finite element modeling," Mathematics and Computers in Simulation, vol. 59, no. 6, pp. 471-488, 2002.

[33] H. Hölschner, M. Tewes, N. Botkin, M. Löhndorf, K. Hoffmann and E. Quandt, "Modeling of pneumatic tires by a finite element model for the development a tire friction remote sensor," Computers and Structures, 2004.

[34] N. Korunovic, M. Trajjanovic and M. Stojkovic, "FEA of tyres subjected to static loading," Journal of the Serbian Society for Computational Mechanics, vol. 1, no. 1, pp. 87-98, 2007.

[35] N. Korunovic, M. Trajanovic and M. Stojkovic, "Finite Element Model for Steady-State Rolling Tire Analysis," Journal of the Serbian Society for Computational Mechanics, vol. 2, no. 1, pp. 63-79, 2008. 